\title{
Instar Susceptibility of the Monarch Butterfly (Danaus plexippus) to the Neogregarine Parasite, Ophryocystis elektroscirrha
}

\author{
K. L. H. Leong, M. A. Yoshimura, H. K. Kaya, and H. Williams \\ Biological Sciences Department, California Polytechnic StateUniversity, San Luis Obispo, California 93407
}

\begin{abstract}
The susceptibility of the monarch butterfly (Danaus plexi ppus) larvae to the neogregarine parasite, Ophryocystis elektroscirrha, was tested in the laboratory. Spore loads recovered from infected monarch butterflies were directly related to the inoculum level, larval stage of the host, and spore age. There was a linear relationship between spores ingested by first instar larvae and spore concentration. Larvae feeding on leaves treated with $0,50,500,5000$, or 50,000 spores averaged $0,0,193,457$, or 1,255 spores, respectively, on the abdomens of the adult butterflies. When first, third, and fifth instar larvae were given 14.5 spores/mg of body weight, there was no significant difference in the spore load of the adults resulting from the first and third instars. However, there were significant differences in the spore load from adults resulting from the first and third instars versus the fifth instar. In addition, 1-year-old spores were not as infectious as fresh spores. Our findings indicate that under field conditions, the first instar is most likely to become infected because one spore appears sufficient to produce a detectable spore load in the adult. Older instars are less susceptible and have fewer opportunities to encounter sufficient viable spores for infection to occur. Thus, vertical transmission appears to be the primary mode of parasite maintenance in natural populations of monarch butterflies.
\end{abstract}

KEY WoRDS: Danaus plexi ppus; Ophryocystis elektroscirrha; monarch butterfly, neogregarine; protozoan parasite.

\section{INTRODUCTION}

Neogregarines in the phylum Apicomplexa, Class Gregarinia, Order Neogregarinorida, are characterized by one or two merogonic schizogonies and a gametogonic and sporogonic schizogony (Weiser and Briggs, 1971; Brooks, 1988; Tanada and Kaya, 1993). Levine
(1988) recognizes six families within the order, one of which is the family Ophryocystidae. This monogeneric family has more than 12 described species that infect the Malpighian tubules of coleopterous insects (Levine, 1988). One exception is the species, Ophryocystis elektroscirrha, which infects hypodermal tissues of the monarch butterfly, Danaus plexippus, and the Florida queen butterfly, Danaus gilippus berenice (McLaughlin and Myers, 1970).

Recent studies showed that a high percentage (50$60 \%$ ) of monarch butterflies, D. plexippus, overwintering in California were infected with O. elektroscirrha (Leong et al., 1992). Very little is known about the impact of this neogregarine on these large winter aggregations of monarch butterflies in California which are considered to be a natural treasure and an endangered phenomenon (Wells et al., 1983). Moreover, laboratory rearing of the monarch butterfly for commercial use increases the prevalence and degree of infection (William J ensen and J ohn Ausland, personal communication) resulting in infected adults with heavy parasite loads that are weak and unable to expand their wings. These affected insects die shortly after emergence. Spores of $\mathrm{O}$. el ektroscirrha are ingested by the monarch butterfly larvae and the hypodermal cells become infected. The parasite, however, does not sporulate until the hosts pupate (MCLaughlin and Myers, 1970). Upon pupation, the parasite rapidly completes morphogenesis in the tissue that is destined to become the setae and scales of the adult butterfly. Thus, the spores of this parasite are found externally over the entire butterfly's body, with the heaviest concentration on the abdomen (Leong et al., 1992). The neogregarine does not appear to influence the butterfly's survival or mating activity during its 6-month stay at the overwintering site (Leong et al., 1992). Under laboratory conditions, butterflies with or without detectable spore loads had similar longevity.

Because of the paucity of information on the interactions of $\mathrm{O}$. elektroscirrha and the monarch butterfly, we initiated a series of laboratory experiments to determine parasite virulence and larval susceptibility to 
infection by this neogregarine. We report herein the (1) effect of spore concentration fed to larvae on the neogr egarine parasiteload in the resulting adult butterflies, (2) viability of spores after passage through the larval intestine, (3) infectivity of 1-year-old spores, and (4) susceptibility of first, third, and fifth larval instars to the protozoan parasite.

\section{MATERIALS AND METHODS}

The butterflies used for the study were laboratory reared $\left(19.4^{\circ} \mathrm{C} \pm 0.4 \mathrm{SE}\right.$ and $\left.44.9 \mathrm{R} . \mathrm{H} . \pm 1.5 \mathrm{SE}\right)$ and free of the neogregarine parasite for two generations. The larvae were fed leaves of the blood flower milkweed, Asclepias curassavica, or the crown flower milkweed, Calotropis gi gantea. The milkweeds were grown in the greenhouse to provide year-round production of food and to eliminate possible contamination by diseased wild butterflies.

Sporeinocula. Unless otherwiseindicated, all spore inocula used for the study were harvested from the abdomens of infected butterflies that were stored individually in envelopes at $5^{\circ} \mathrm{C}$ for less than a month. The spores were recovered from infected butterflies using a modified methodol ogy described by Leong et al . (1992). The abdomen was placed in a $15-\mathrm{ml}$ centrifuge tube containing $2 \mathrm{ml}$ of $0.05 \%(\mathrm{v} / \mathrm{v}$ ) wetting agent (Tween 20; J . T. Baker Chemical, Phillipsburg, NJ) in deionized water and washed for spores by agitating with a vortex mixer for $1 \mathrm{~min}$, letting stand for $5 \mathrm{~min}$, and reagitating for another minute. The abdomen was removed and the wash suspension was centrifuged for $10 \mathrm{~min}$ at 3000 rpm with a bench-top centrifuge (Beckman GS-6 Centrifuge; Beckman, Palo Alto, CA). The supernatant was discarded, $0.2 \mathrm{ml}$ of the $0.05 \%$ wetting solution was added, and the suspension was agitated for $2 \mathrm{sec}$ on a vortex mixer to resuspend the pellet. The number of neogregarine spores/ml recovered was determined with a hemocytometer. In all cases, control treatments contained $0.05 \%$ wetting agent.

Larval rearing. The first to third instar larvae were maintained on milkweed bouquets. A bouquet consisted of one or two blood flower milkweed shoots ( 15 to $20 \mathrm{~cm}$ ) inserted through the middle of a plastic lid for a 473-ml drinking cup and secured to the lid with cotton. The cutting was inserted into an opening of a parafilmcovered 150-ml beaker filled with water, and the shoot was adjusted to an upright position. The 473-ml cup, modified by replacing the bottom with a Kimwipe tissue (secured with tape), was then inverted over the milkweed bouquet and snapped onto the lid. The larvae were transferred to fresh bouquets every 2 days.

When larvae reached the fourth instar, the lid and parafilm-covered beaker were replaced with a new plastic lid cover. The larvae were fed the crown flower milkweed leaves daily within these containers until the fifth instar, at which timethey were transferred one per cup to inverted 355-ml clear plastic tumblers with plastic lids. Five holes were made in the bottom of the plastic cups for aeration. The larvae were fed daily within these clear plastic cups until they pupated. Upon adult ed osion, the butterflies were harvested and their abdomens examined for spores, using the wash method described above.

Effect of larval spore concentration on adult parasite load. In the first experiment, first instar larvae were exposed to milkweek bouquet leaves sprayed with one of five spore suspensions: $0,50,500,5000$, and 50,000 spores $/ \mathrm{ml}$. Starting at the lowest concentration, each treatment, replicated three times, was applied to the leaves using a hand atomizer (DeVilbiss atomizer 15, The DeVilbiss Co., Somerset, PA) until runoff and allowed to air dry before the larvae were introduced. A total of 15 larvae (5 larvae/replication) were used for each of the four spore suspension levels and control. The larvae were allowed to feed for $48 \mathrm{hr}$ before being transferred to clean milkweed bouquets and reared using the protocol described earlier.

In the second experiment, third instar larvae were given five levels of spore inocula. The spore level was based on exposing each larva to 14.5 spores/mg of body weight. Because the mean weight of the third instar was $45.4 \mathrm{mg} \pm 0.35 \mathrm{SE}$, the maximum inoculum was 658 spores/larva. Succeeding spore levels were halved so that each larva received 329, 165, or 82 spores, with the control larva receiving 0 spores. Nine larvae were used for each of the five spore levels. In addition, 1-year-old spores stored at $5^{\circ} \mathrm{C}$ were tested to determine their viability. Nine larvae were each given 658 of these spores.

Each inoculum was applied in $100 \mu$ to a half leaf of A. curassavica. The suspension was air dried, after which each larva, confined in a 50-ml plastic vial, was given a half leaf with the appropriate spore inoculum. The cap of the vial was perforated with holes for aeration. Upon consumption of the leaf, the larvae were transferred to clean milkweed bouquets (3 larvae/ bouquet, 9 larvae total per inoculum level) and reared using the same protocol as that described earlier.

Viability of spores after passage through the larvae Infectivity of spores after passage through the larval intestine was determined by collecting the feces from larvae in each of the five inoculum levels in the second experiment described above. The feces from each inoculum level were pooled and each pooled sample was placed into a separate $15-\mathrm{ml}$ centrifuge tube. Three milliliters of $0.05 \%$ Tween 20 was added and mixed until a suspension was achieved. An aliquot from each inoculum level was examined at low power (10× objec- 
tive lens) with a compound microscope to verify the presence of spores.

A $0.5-\mathrm{ml}$ aliquot of the fecal suspension was spread onto half a leaf of $A$. curassavica and air dried. The inoculated half leaf was placed in a 50-ml capped plastic vial containing a third instar larva. After the larva had consumed this leaf, it was transferred to a clean milkweed bouquet. Five larvae (replicate) were used for each of the five treatment levels. The larvae were reared using the same protocol as described earlier.

Instar susceptibility. The first, third, and fifth instars were tested to determine their susceptibility to the neogregarine. Average body weights were $0.7 \mathrm{mg} \pm$ $0.03 \mathrm{SE}, 61.9 \mathrm{mg} \pm 1.56 \mathrm{SE}$, and $770.8 \mathrm{mg} \pm 6.47 \mathrm{SE}$ for the first, third, and fifth instars, respectively. Larvae were given 14.5 spores/mg of body weight (approximately 10 spores per first instar larva). Nine larvae (replicate) were used for each of the three developmental stages and their respective controls. The inoculum for first instar was applied in 2- $\mu$ l aliquots to a given area of $\mathrm{C}$. gigantea and allowed to air dry. This inoculated leaf area was then enclosed by a 3.2-ml shell vial (7 mm inner diameter) containing a single larva. After the larva had consumed the entire enclosed leaf area within the vial, it was transferred to clean milkweed bouquets ( 3 larvae/bouquet, 9 larvae total). The inocula for the third and the fifth instars $(2-\mu l$ and $50-\mu l$ aliquots, respectively) were applied to half leaves of $A$. curassavica and air dried. The inoculated half leaf was placed in a 50-ml plastic vial containing a single larva. After consuming the leaf, the larva was transferred to clean milkweed bouquets (3 larvae/bouquet, 9 larvae/ instar). The larvae were reared using the same protocol described earlier.

Statistical analyses. The data were analyzed using the statistical program of Biostat 1 for ANOVA, linear regression, and t test (Pimentel and Smith, 1990).

\section{RESULTS}

Effect of larval spore concentration on adult parasite load. In the first experiment, a linear relationship was exhibited between the concentration of spores sprayed on the leaves and the number of spores recovered from the adult butterflies $(y=-545.1+404.3 x$, $r^{2}=0.88$ ). The average number of spores recovered from the abdomens of adults ranged from 1255 spores for those treated with 50,000 spores $/ \mathrm{ml}$ to 0 spores at 50 spores $/ \mathrm{ml}$. I nocula levels of 0, 50, and 500 spores $/ \mathrm{ml}$ resulted in adults that appeared normal. I nocula levels of 5000 and 50,000 spores $/ \mathrm{ml}$ resulted in 7.1 and $91.7 \%$ of the emerging adults (Table 1 ) that were heavily infected and weak and could not separate from their chrysalis or fell to the container's floor. These adults

\section{TABLE 1}

Number of Ophryocystis elektroscirrha Spores Recovered from Abdomens of Monarch Butterflies Treated during Their First Larval Instar with Leaves Sprayed with 0, 50, 500, 5000 , and 50,000 Spores

\begin{tabular}{|c|c|c|c|c|}
\hline $\begin{array}{l}\text { Treatment } \\
\text { (spores/ml) }\end{array}$ & $\mathrm{N}$ & $\begin{array}{l}\text { Percentage } \\
\text { with spores }\end{array}$ & $\begin{array}{l}\text { Abdomen } \\
\text { spore } \\
\text { load } \\
(\bar{x} \pm \mathrm{SE})\end{array}$ & $\begin{array}{c}\text { Percentage } \\
\text { of deformed } \\
\text { adults }\end{array}$ \\
\hline 50 & 12 & 0 & 0 & 0 \\
\hline 500 & 12 & 42 & $193 \pm 83$ & 0 \\
\hline 5000 & 14 & 100 & $457 \pm 90$ & 7.1 \\
\hline 50,000 & 12 & 100 & $1255 \pm 285$ & 91.7 \\
\hline 0 & 14 & 0 & 0 & 0 \\
\hline
\end{tabular}

appeared wet and were covered with spores along with a tar-like substance that may have been melanin. Their wings did not expand and their abdomens were shriveled.

In the second experiment, the parasite load of butterflies when treated during the third instar was directly related to the level of inoculum $(y=61.6+111.1 x$, $r^{2}=0.91$ ). The mean number of spores (spore load) recovered from the adults at various concentration levels, however, was not significantly different (Table 2).

Adults treated during the first instar with 1-year-old inoculum had significantly fewer spores (123 \pm 22.4$)$ than those treated with fresh spores $(665 \pm 147.8$; $\mathrm{t}=3.6, \mathrm{P}<0.01, \mathrm{df}=8$ ). Spore loads produced with the 1-year-old inoculum were one-fifth the load produced with the fresh inoculum.

Viability of spores after passage through the larvae. Examination of fecal material of treated larvae showed the presence of few neogregarine spores ( 1 or 2 spores/5 random microscopic field using 100× magnification). No spores were recovered from the abdomens of adults resulting from larvae fed fecal contaminated leaves.

Instar susceptibility. Adults of larvae treated during the first and third instars had significantly

TABLE 2

Number of Ophryocystis elektroscirrha Spores Recovered from Abdomens of Adult Butterflies Treated during Third Instar Based on 14.5 Spores/mg of B ody Weight

\begin{tabular}{cccc}
$\begin{array}{c}\text { No. of } \\
\text { spores } \\
\text { fed per } \\
\text { individual }\end{array}$ & N & \% with spores & $\begin{array}{c}\text { Abdomen } \\
\text { spore load } \\
(\overline{\mathrm{x}} \pm \mathrm{SE})\end{array}$ \\
\hline 658 & 9 & 100 & $496 \pm 127$ \\
329 & 9 & 100 & $438 \pm 123$ \\
165 & 9 & 100 & $229 \pm 84$ \\
82 & 9 & 89 & $176 \pm 70$ \\
0 & 9 & 0 & 0 \\
\hline
\end{tabular}

Note. The average body weight of third instar was $45.4 \mathrm{mg} \pm 0.35$. 


\section{TABLE 3}

Instar Susceptibility Based on Number of Ophryocystis elektroscirrha Spores Recovered from Abdomens of Adults Treated with 14.5 Spores/mg of Body Weight during the First, Third, and Fifth Larval Instars

\begin{tabular}{lcccc}
\hline Instar & $\begin{array}{c}\text { Body } \\
\text { weight }(\mathrm{mg}) \\
(\overline{\mathrm{x}} \pm \mathrm{SE})\end{array}$ & $\mathrm{N}$ & $\begin{array}{c}\text { Percentage } \\
\text { with spores }\end{array}$ & $\begin{array}{c}\text { Abdomen } \\
\text { spore load } \\
(\overline{\mathrm{x}} \pm \mathrm{SE})\end{array}$ \\
\hline First & $0.70 \pm 0.03$ & 9 & 100 & $665 \mathrm{a} \pm 148$ \\
Third & $61.9 \pm 1.56$ & 9 & 100 & $495 \mathrm{a} \pm 127$ \\
Fifth & $770.8 \pm 6.47$ & 9 & 89 & $94 \mathrm{~b} \pm 59$ \\
\hline
\end{tabular}

a None of the controls in each of the three instars were infected. $\mathrm{N}=9$ for each instar.

b Means with different letter are significantly different $(F=6.22$, $P=<0.01, d f=2,24$ ).

$(\mathrm{F}=6.22, \mathrm{P}=<0.01, \mathrm{df}=2,24)$ mores spores $(665$ and 495, respectively) than those treated during the fifth instar (94) (Table 3). Although not significant, more spores were recovered from butterflies treated during the first than during the third instar.

\section{DISCUSSION}

The number of spores recovered from adults was directly related to the inoculum levels fed to the larvae and to the age of the larvae. Larvae treated during the first or third instars produced adults that showed a strong linear relationship between the inoculum level and spore load. Hence, the higher inoculum levels consumed by the larvae resulted in higher spore loads on the adults. A high percentage (91.7\%) of adults with a mean abdominal spore load of 1255 were weak and deformed and died shortly after emergence. When equivalent inoculum levels (based on spores/mg) were given to the first, third, and fifth instars, the larvae in each instar produced infected adults. The degree of infection, based on spore loads on the abdomen, was directly associated with the duration within the host; larvae infected during the earlier instars produced adults with greater numbers of spores than those infected at a later instar.

Although all larval stages tested were susceptible to the neogregarine, the most probable stage that would be infected in the field would be the first instar. Experimentally, first instars weigh an average of 0.7 $\mathrm{mg}$ and an estimated one spore/first instar larva was sufficient to cause detectable infection (spores recovered by the wash method). Consumption of a single spore by the first instar is highly possible because we have frequently observed eggs from infected adults with one or more spores adhering to the chorion. Upon eclosion from the egg, the monarch larva often consumes the entire chorion. Such behavior ensures the perpetuation of the parasite in the monarch butterfly population. Infection of later instars is unlikely be- cause the probability of older larvae encountering a high enough spore level for infection (based on spores recovered by the wash method) to occur is remote. M oreover, infected larvae are not the source of infection because sporulation occurs only during the pupal stage (McLaughlin and Myers, 1970), and our study has shown that spores passed through the larval digestive system appear to be noninfectious.

Infected adult males or females could contaminate the larval food source with spores if mating occurs on the milkweed plant, resulting in infection of older instars. Leong (1995) observed canopy mating among overwintering butterflies. The activity between the sexes during mating could cause the spores on the scales to detach and contaminate the milkweed leaf surfaces. Although sexual transmission of spores from infected males to healthy females has not been demonstrated, it may be another possible means of spore transfer resulting in contamination of the egg. Liu et al. (1974) observed spores of Apicystis (= Mattesia) bombi in the spermatheca of mated, overwintering bumblebee queens. They hypothesized that this may bea means of contaminating the bumblebee brood.

The passive transmission of spores from infected to healthy butterflies in clusters is not likely, since the proportion of individuals with detectable spore loads did not change significantly during a 6-month overwintering period (L eong et al., 1992).

Severely infected individuals as observed by McLaughlin and Myers (1970) and monarch breeders (William J enson and J ohn Ausland, personal communication) probably occur at a low frequency under field conditions. A female generally deposits eggs singly on the underside of a leaf. In Paso Robles, San Luis Obispo County, California, the number of eggs on a single milkweed plant in the field seldom exceeded six eggs (Leong, unpublished data). The low larval density minimizes competition for food and, perhaps, ensures maintenance of the neogregarine parasite in the population. We have shown that a first instar larva consuming approximately 10 spores produces adults with a mean abdominal spore load of 665. Females with this spore load may be capable of depositing eggs with sufficient inoculum to produce severely infected individuals. Under field conditions, however, some of these spores may be inactivated by environmental factors (UV light or desiccation) or may not adhere to the leaf surface. Even if heavily infected larvae survive and reach adulthood, the chances of the adult surviving will not be very good based on laboratory observations.

Monarch breeders have often encountered severely infected individuals after just three generations of rearing the butterflies. Conditions that produce severely infected butterflies may be attributed to the cultural practices of these breeders. The butterflies are forced to oviposit on a common milkweed host in 
densities not observed in nature. This allows eggs of infected females to be oviposited with those of the uninfected ones (McLaughlin and Myers, 1970). After a few generations, the majority of the females would be infected and the inoculum level on the milkweed used for oviposition would be sufficient to produce severely infected individuals.

Our study has demonstrated that vertical transmission of 0 . elektroscirrha is the most probable because of the high susceptibility of the first instar larva to the neogregarine spore. Although infected adults could contaminate the food supply, older instars need to consume a fairly high number of spores before infection occurs. Thelack of larval tolarval (horizontal) transmission further suggests that vertical transmission is the primary means of parasite maintenance in monarch butterfly populations. U nder laboratory breeding conditions, however, spores on the scales of the butterfly are the probable source of contamination resulting in the rapid spread of the parasite throughout the laboratory population.

\section{ACKNOWLEDGMENT}

Wethank Mark Kubinski for his critical review of and comments on the manuscript.

\section{REFERENCES}

Brooks, W. M. 1988. In "CRC Handbook of Natural Pesticides," Vol. 5, "Microbial Insecticides," Part A, "Entomogenous Protozoa and Fungi" (C. M. Ignoffo, Ed.), pp. 1-149. CRC Press, Boca Raton, FL.

Leong, K. H. L. 1995. Initiation of mating activity at the tree canopy level among overwintering monarch butterflies in California. Pan. Pac. Entomol. 71, 68-71.

Leong, K. L. H., Kaya, H. K., Yoshimura, M. A., and Frey, D. 1992. The occurrence and effect of a protozoan parasite, Ophryocystis el ektroscirrha sp. $n$. McLaughlin and Myers (Neogregarinida: Ophryocystidae) on overwintering monarch butterflies (Danaus plexippus (L.)) from two California winter sites. E col. Entomol. 17, 338-342.

Levine, N. D. 1988. “The Protozoan Phylum Apicomplexa," Vol. 1. CRC Press, Boca Raton, FL.

Liu, H. J., Macfarlane, R. P., and Pengelly, D. H. 1974. Mattesia bombi $n$ sp. (Neogregarinida: Ophrocystidae), a parasite of Bombus (Hymenoptera: Apidae). J . I nvertebr. Pathol . 23, 225-231.

McLaughlin, R. E., and Myers, J . 1970. Ophryocystis elektroscirrha sp. n., a neogregarine pathogen of the monarch butterfly Danaus plexippus (L.) and the Florida queen butterfly D. gilippus berenice Cramer. J . Protozool. 17, 300-305.

Pimentel, R., and Smith, J . 1990. "Biostat I: A Univariate Statistical Tool Box," 2nd ed. Sigma Soft. Placentia, CA.

Tanada, Y., and Kaya, H. K. 1993. "I nsect Pathology."Academic Press, San Diego, CA.

Weiser, J ., and Briggs, J. D. 1971. Identifications of pathogens. In "Microbial Control of Insects and Mites" (H. D. Burges and N. W. Hussey, Eds.), pp. 13-66. Academic Press, New York.

Wells, S. M., Pyle, R. M., and Collins, N. M. 1983. "The IUCN I nvertebrate Red Book." I nternational Union for Conservation of Nature and Natural Resources, Gland, Switzerland. 